August Weismann, von Uexküll, T. H. Morgan, E. B. Wilson, Albert Szent Györgji, Jean Brachet, Marcel Florkin and J. Z. Young.

Anton Dohrn had financed the Station from four sources-receipts from visitors to the Aquarium (then as now housed in the Station) contributions from institutes and governments who rented 'working places' for visiting members from their institutes, proceeds from the sale of preserved marine animals, and contributions from patrons. This private status of the Station came to an end as a result of reorganisation under a new Administrative Council formed in 1975. Two directors have served under this Council, Alessandro Barlaam and the present director, Alberto Monroy.

Both directors were aware of the importance of the archival material at the Station. Several years ago the archivist Christiane Groeben sorted and catalogued the scientific correspondence, photographs, and other documents with the aid of funds from the Dohrn family Foundation and the Deutsche Forschungsgemeinschaft. In 1974 an exhibition of this material was held at the Station; copies of the excellent catalogue are still available.

As the existence of this remarkable collection of some 15,000 letters is becoming more generally known Groeben's task is growing. The historical work of the Station is being expanded with the formation of a Research Group consisting of Bernardino Fantini of the Institute of Genetics in Rome, Christiane Groeben and the Station's librarian Walter Groeben.

The aim of the group is to promote the history of embryology, cell biology, biochemistry, neurophysiology and taxonomy, with special attention to the social and cultural role of research institutes. In addition to the organisation of the scientific correspondence at the Station, scientists who have had connections with the Station will be interviewed. It is planned to start with J. Brachet, A. Monroy, G. Montalenti, $M$. Aloisi and J, Z. Young.

At the first of a proposed series of biennial summer schools, this year on biochemical and molecular embryology*, Jean Brachet gave a spirited account of his involvement in chemical embryology. The ways in which the subject of the distribution of nucleic acids in the cell was affected by the lack of congruence between the disciplines of biochemistry and histochemistry, and the impact this had on his scientific career came over clearly.

Robert Olby is in the Division of the History and Philosophy of Science at the University of Leeds.

\title{
Petrified cotton?
}

from F. L. Vogel and J. N. Zemel

A NOVEL material has just made its debut which provides an artificial counterpart to natural petrified materials which preserve the fine detail of the original perishable structure. Natural petrified wood for example, is formed when the original wood is infiltrated by silicious matter which converts it into a stony substance preserving the original structure. There are no comparable processes used industrially that convert organic materials to a more permanent form. The recent paper by $T$. L. Ward and R. R. Benerito (Thin Solid Films 53, $73 ; 1978)$ is therefore particularly interesting. They describe the unusual transformation of ordinary cotton fibre into a glassy material reminiscent of the permineralisation of wood.

In the Ward-Benerito process, cotton fabric is first soaked in a sodium plumbite solution after which it is dried, placed on a glassy substrate and heated to temperatures as high as $600{ }^{\circ} \mathrm{C}$. During heating, the treated cotton initially carbonises to a black colour. As the temperature is raised, it picks up silicious material from the substrate and becomes yellow. At $600{ }^{\circ} \mathrm{C}$ the carbon skeleton is impregnated with silica and is converted to a glassy substance reproducing details of the original fabric. The authors demonstrated the results of this process with many artefacts including labels and decorations on bottles, adhesives between glasses and free standing thin films.

These results are interesting as they indicate the existence of a novel material. Still more interesting perhaps is the origin of the process which produces it. Ward and Benerito examined the composition of the plumbite-treated material using a variety of analytic techniques such as $\mathrm{X}$-ray diffraction, optical and electron microscopy (TEM and SEM), ESCA, EDAX, DTA, X-ray fluoresence and atomic absorption. These studies indicated that lead was uniformly distributed in both the unheated and the transformed cotton. Furthermore, it was observed that the residual carbon concentration in the charred cotton

His modest description of his work as the correction of a series of errors was accompanied by his strong claim for the importance of his work on the transmission of information from DNA to the site of protein synthesis by long-lived RNA molecules. His statements on this subject are to be found was six carbon atoms to one lead atom. Since lead is not known to form a carbide, this result may be taken as an indication of an interstitial or intercalation compound described in a recent popular review (Fischer \& Thompson Phys. Today July, 1978). This conjecture is supported by the following observations.

When cellulosic materials are charred, a high defected hexagonal layered structure forms. While this is not a true graphite, it may be sufficiently similar that some degree of intercalation is possible.

The process of interstitial insertion can in itself improve the crystal perfection of the hexagonal layered structure resulting in a closer approach to a graphitic material.

The relatively low temperature of the process suggests that the diffusion occurs by an interstitial mechanism.

Silicates are known to form layered compounds, one common example of which is mica.

The mechanism suggested by this combination of facts is that intercalation of lead separates the spacing between the roughly formed hexagonal layers sufficiently to allow interstitial diffusion of the silicious materials from the substrate.

Neither the 'petrified cotton' nor the process to produce it arose in response to a stated need. As such, it is a fascinating example of a fundamental study of a technical substance. Since long term stability of cellulosic materials such as wood, paper and cotton is notoriously poor, it might be expected that permineralisation of these substances by the WardBenerito technique could be used. Diverse examples of this would include document preservation, converted wood as a decorative building material, or lacy objets d'art that could be produced no other way. As with any new material, uses will probably be found that cannot be foreseen at this early stage.

F. L. Vogel and J. N. Zemel are in the Department of Electrical Engineering and Science, University of Pennsylvania.

in his Weizmann Memorial Lecture, The Biological Role of the Nucleic Acids, delivered in April 1959 and published in 1960. The discovery of soluble RNA and microsomal RNA did not solve what "for the geneticist and immunologist [was] the major problem", wrote Brachet, "the mech- 